\title{
Yellow Fever Vaccination: An Issue for Non-endemic Tropical Countries
}

\author{
Viroj Wiwanitkit ${ }^{1,2,3^{*}}$ \\ ${ }^{1}$ Hainan Medical University, Hainan, China \\ ${ }^{2}$ Dr DY Patil University, Pune, India \\ ${ }^{3}$ Faculty of Medicine, University of Nis, Nis, Serbia
}

Corresponding Author: Viroj Wiwanitkit, MD, Professor, Wiwanitkit House, Bangkhae, Bangkok, Thailand. Tel: +66-24132436, Email: wviroj@yahoo.com

Received October 18, 2017; Accepted November 5, 2017; Online Published November 15, 2017

Citation: Wiwanitkit V. Yellow fever vaccination: an issue for non-endemic tropical countries. Int J Travel Med Glob Health. 2018;6(2):86-87. doi:10.15171/ijtmgh.2018.17.

\section{Dear Editor,}

Yellow fever is an important mosquito-borne infection. This disease is endemic in several tropical countries in Africa and South America. It is serious and can result in death. This disease can be prevented, and the best preventive measure is vaccination. At present, yellow fever vaccination is mandatory for people living in endemic countries, and it is the rule for travelers to endemic countries. An interesting concern is the practice of vaccinating travelers from non-endemic areas for yellow fever. ${ }^{1}$ The situation in tropical Southeast Asia where yellow fever is non-endemic should be discussed. Interestingly, mosquitoes can be vectors for yellow fever, and it is feasible for the virus to be transmitted by them in tropical Southeast Asia. In addition, the climate in tropical Southeast Asia is the same as that of tropical Africa and South America. Hence, if a traveler from Southeast Asia visits an endemic area and carries the disease back to his/her home, there is a chance of further transmission. To date, there has been no report of this disease being imported from an endemic area to Southeast Asia. Nevertheless, a recent report described the disease being imported in China, a country neighboring Southeast Asia. ${ }^{2}$

At present, the availability of the yellow fever vaccine is limited in Southeast Asia. Here, a case study from Thailand, a tropical, non-endemic country in Southeast Asia, is discussed. Thailand has fewer than 10 medical centers that can perform the yellow fever vaccination. Moreover, Thailand has only a limited number of specialists in travel medicine. General practitioners usually lack knowledge of yellow fever and its vaccine due to a lack of content in the present medical curriculum. Immigration focuses on disease control; thus, strict control is available at international airports, but not at land border posts. Problems with the control of yellow fever exist in Thailand, similar to other tropical Southeast Asian countries. ${ }^{3}$ A few hundred people are vaccinated annually at medical centers in Thailand. An interesting concern is the adverse effects of the yellow fever vaccine. To date, there is no report on the adverse effects of the vaccine except one regrettably fatal case of a patient with an underlying HIV infection. ${ }^{4}$ The case had a fatal neurological disease -the disease is develop due to vaccination- and was later diagnosed for asymptomatic HIV infection. ${ }^{4}$ Furthermore, HIV infection is endemic in Thailand, similar to other developing countries, and the risks related to yellow fever vaccination in asymptomatic HIV-infected persons is a compelling issue. At present, there is no screening for HIV before the yellow fever vaccine is given, and this might be the greatest risk for any setting with a high prevalence of HIV.

Thailand as a model has many weak points that can increase the risk of the emergence of yellow fever there. Currently, international travel is increasing, and yellow fever transmission is an emerging threat in new settings. In non-endemic tropical countries, disease control should be intensified, and vaccination against yellow fever should be strictly managed. Pre-vaccination screening to rule out contraindications should also be an important point in the administration of the yellow fever vaccine.

\section{Conflict of Interest Disclosures}

None.

Ethical Approval

Not applicable.

\section{Funding/Support}

None.

Copyright $(C 2018$ The Author(s). This is an open-access article distributed under the terms of the Creative Commons Attribution License (http:// creativecommons.org/licenses/by/4.0), which permits unrestricted use, distribution, and reproduction in any medium, provided the original work is properly cited. 


\section{References}

1. Arrazola MP, Serrano A, López-Vélez R. Vaccination for international travelers. Enferm Infecc Microbiol Clin. 2016;34(5):315323. doi:10.1016/j.eimc.2016.01.009.

2. Chen Z, Liu L, Lv Y, et al. A fatal yellow fever virus infection in China: description and lessons. Emerg Microbes Infect. 2016;5(7):e69. doi:10.1038/emi.2016.89.
3. Wiwanitkit V. Yellow Fever in Southeast Asia: A Concern After the Emerging of the First Imported Case in China. Int J Infect. 2017. doi:10.5812/iji.14139.

4. Kengsakul K, Sathirapongsasuti K, Punyagupta S. Fatal myeloencephalitis following yellow fever vaccination in a case with HIV infection. J Med Assoc Thai. 2002;85(1):131-134. 